\title{
Participants' preferred choice of practitioner for orofacial symptoms
}

SADJ August 2017, Vol 72 no 7 p315 - p322

S Indermun', Q Isaacs ${ }^{2}$, R Mulder ${ }^{3}$

\section{ABSTRACT}

Background: Patients seeking treatment from general medical practitioners (GP) may be unaware or ill-informed that dentists are the more appropriate professionals to manage their orofacial symptoms, being able to diagnose and treat, or, if deemed necessary, appropriately refer.

Aims: To: (1) determine from a group of patients ( $n=$ 37) their initial preference of health care provider, when seeking treatment for orofacial symptoms (2) establish their awareness of the appropriate proficiency of the dentist, and, (3) determine the referral pathway before patients attended the Tygerberg Oral Medicine Clinic.

Methods: A cross sectional study design; quantitative data was collected by a modified previously published Bell-questionnaire with closed-ended questions.

Results: $53.8 \%$ of patients preferred a dentist to attend to a mouth or jaw problem and $46.1 \%$, a GP. When clinical scenarios were posed, all directly related to the scope of practice of the dental practitioner, it was of concern that 47.3\% chose the GP and $52.67 \%$ chose the dentist.

Conclusion: Patients initially chose the GP for many orofacial diseases, although they indicated at the Oral Medicine clinic that the dentist had the most relevant knowledge. Participants did not associate some of the orofacial symptoms with the training of dentists.

Keywords: Orofacial symptoms, dentist, general medical practitioner (GP), proficiency, participant referral.

\section{INTRODUCTION}

A common goal of the health care sector is to serve the public with the best possible care. ${ }^{1}$ Problems arise

1. Suvarna Indermun: $B C h D$. Department of Oral Medicine and Periodontics, Faculty of Dentistry, University of the Western Cape, South Africa.

2. Qaanita Isaacs: $B C h D$. Department of Oral Medicine and Periodontics, Faculty of Dentistry, University of the Western Cape, South Africa.

3. Riaan Mulder: BChD, MSc. Lecturer, Division of Operative Dentistry and Endodontics, Department of Orthodontics and Paediatric Dentistry. University of the Western Cape, Tygerberg, Cape Town.

Corresponding author

Suvarna Indermun:

Department of Oral Medicine and Periodontics, Faculty of Dentistry,

University of the Western Cape. Private Bag X1, Tygerberg, 7505 South

Africa. Cell: 082789 0672. E-mail: suvarna.indermun@gmail.com

\section{ACRONYMS}

GP: General Medical Practitioner

when patients are unsure about who should be their appropriate "first choice" practitioner to provide care. Dentistry and Medicine are different professions, the former exercising treatment mainly of the mouth and teeth, whereas the latter accepts responsibility for the rest of the human body. ${ }^{2}$ However, there is an obvious physical overlap as the oro-dental complex is an integral part of the body. ${ }^{3}$ Consequently, patients are often conflicted when deciding who to consult first for orofacial problems.

Most patients who seek medical attention from their general medical practitioners (GP) for orofacial diseases are either unaware or ill-informed of the fact that the dentist is the more appropriate professional for treating the oral presentation of symptoms, with a subsequent referral if deemed necessary. ${ }^{4}$ For many, the GP is the first person consulted for advice regarding the treatment and management of dental or oral related pain. ${ }^{5}$ Reported reasons for this include: poor patient education, lack of after-hours dental care, non-classic presentation of dento-facial pain, financial considerations, and for the most part, the participant's perception of their GP as the primary coordinator of integrated and total health care. ${ }^{5}$

Many oral conditions are tooth-related and many systemic conditions may have a dental dimension, as an influence or manifestation. Although qualified dentists successfully manage orofacial conditions, many patients first consult their GP's, who then refer them to a hospital or an earnose-and-throat specialist (ENT) instead of a dentist. ${ }^{6}$

The public often holds the view that dentists only fill cavities in teeth and provide dentures and that all other oral problems are the domain of a medical doctor. ${ }^{7}$ Yet the scope of dentistry enables qualified dentists to perform a wide range of procedures relating to oral and peri-oral regions. ${ }^{8}$ Modern dentists are well-trained, qualified and equipped to successfully treat many orofacial diseases. Dentists will regularly make sound judgments and promptly refer patients when management and/or treatment are beyond their skills and require specialist care. ${ }^{9}$

A dental consultation should include screening and treatment. ${ }^{10}$ For example, dentists recognise oral premalignant lesions and/or HIV indicators often before signs 
and symptoms manifest. This allows early and urgent referrals, ${ }^{11}$ which results in appropriate treatment with an improved prognosis. ${ }^{12}$

A study investigated current practices detecting lesions and referral of patients by general medical practitioners. ${ }^{6}$ Over half of these GPs (57\%) stated they would consider urgent referral if an intra-oral lesion had been present for four to five weeks, with $37 \%$ expressing the need for referral after two to three weeks. The clear majority of GPs indicated that they would refer to general hospitals (74\%) while a further $22 \%$ indicated that they would use a dental hospital facility. Of those GPs who indicated that they would refer to general hospitals, $83 \%$ said they would choose an Oral and Maxillofacial Surgery unit, with a further 15\% opting for an Ear Nose and Throat specialist (ENT). Only 1\% referred participants to a General Surgery unit. Most dental respondents (54\%) referred suspicious lesions after two to three weeks, with a further $30 \%$ doing so after four to five weeks' observation. While the majority of dental respondents indicated they normally referred to a dental hospital (56\%), a substantial number contacted general hospitals (43\%). Of the latter group, the department most commonly selected was the Oral and Maxillofacial Surgery unit. ${ }^{6}$

Another study revealed that the clear-out majority of both GPs and dentists selected Oral Medicine and Oral and Maxillofacial Surgery as their preferred points of referral for participants with suspected oral cancer. It was also evident that dentists selected Oral Medicine Specialists (Periodontist) more often than Maxillofacial and Oral Surgery specialists as their preferred point of referral..$^{13}$ Oral Medicine has been described as a specialty that bridges the traditional areas of health between Dentistry and Medicine. This interface is concerned with the diagnosis and management of (non-dental) pathology affecting the oral and maxillofacial region..$^{14}$ Since dentists commonly refer to an Oral Medicine Specialist, ${ }^{13}$ they can be seen as an important link between medical doctors and dentists. A referral to a Maxillofacial and Oral Surgeon or Periodontist is accurate, however for soft tissue pathology and ulcerations, an Oral Medicine Specialist can help avoid unnecessary transfers and costs to the participant. ${ }^{14}$ a dentist for specific dental complaints. The participant cited being unaware of the dental relevance of some of the dental complaints. The participants also perceived medical practitioners as having had more training and therefore being more capable in dealing with non-dental orofacial complaints. $^{12}$

After reviewing the above literature, it was evident that patients were often not aware of the broad education of dentists and the wide scope of dental practice..$^{12}$ Patients were unaware of the reality that upon graduation the dentist was proficient in diagnosing and managing oral mucosal diseases. ${ }^{9}$

\section{RESEARCH AIM}

1. To determine the initial preferential choice of participants for health care providers to manage orofacial symptoms.

2. To establish the awareness of participants of the proficiency of the dentist for orofacial symptoms.

3. To determine the referral pathway followed by participants before attending the Tygerberg Oral Medicine Clinic at the Dental Faculty of the University of the Western Cape.

\section{DEFINITION OF KEY TERMS}

\section{Proficiency}

For purposes of this study, the meaning of clinical proficiency will denote the following:

"a dentist who is competent in decision-making, clinical reasoning and judgement to develop a differential, provisional or definitive diagnosis by interpreting and correlating findings from the history, clinical and radiographic examination and other diagnostic tests, taking into account the social and cultural background of the individual. The dentist will also be competent to participate in the diagnosis and proper referral of the participant with life-threatening oral mucosal diseases". ${ }^{9}$

\section{Patient}

Term used in the literature denoting individuals receiving medical and/or dental treatment.
A study aimed to determine participants' preference of medical or dental practitioners for a variety of dental and non-dental orofacial symptoms was conducted. It investigated' the perceptions of participants of the training, experience, and skills of medical and dental practitioners in treating orofacial symptoms. ${ }^{12}$ Participants had to make a choice of which practitioner, medical or dental, they would consult with for a variety of orofacial symptoms. The results revealed that most of the participants preferred to consult a GP rather than

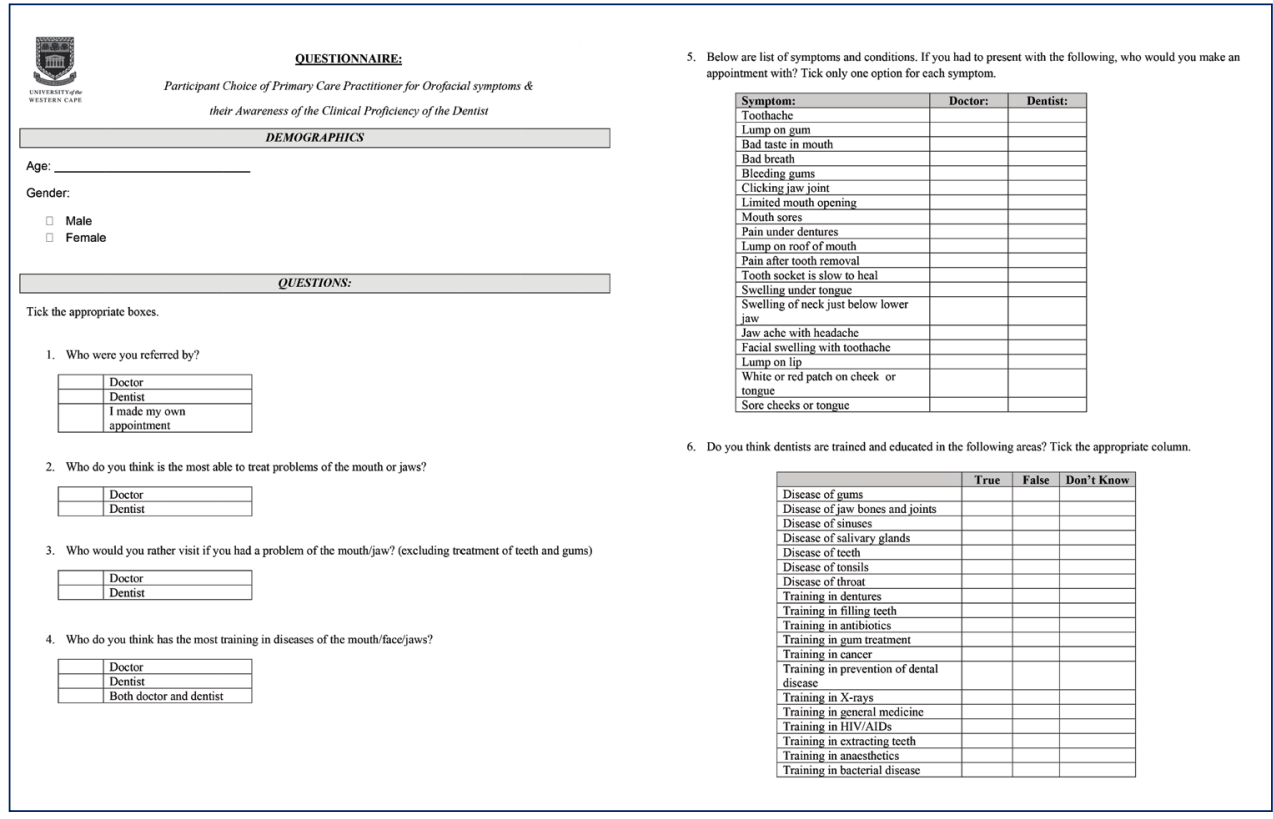

Figure 1: Questionnaire as adopted from Bell et al. (2008). 
Participant

Individuals receiving treatment at the Tygerberg Oral Medicine Clinic and who partook in the study.

\section{MATERIAL AND METHODS}

\section{Research design}

This was a cross sectional study design; quantitative data was collected through the use of a modified previously established and published Bell-questionnaire ${ }^{12}$ with closed-ended questions (Figure 1). The participants ( $n=37$ ) were requested to answer various questions on their perception of the preference and ability regarding from which practitioner they would prefer receiving treatment (GP or dentist). Various orofacial disease scenarios were tabulated and the participant was requested to indicate whether they would visit the dentist or the GP. The last component was the participant perception of the knowledge that the dentist has regarding various orofacial and other non-dental scenarios. A 'don't know' option was provided, since dentistry has a wide scope of practice and the participant might not have had profound knowledge of all the non-dental training dentists receive.

\section{Study population}

The UWC Oral Medicine clinic treats 360 new participants on average each year and the final sample size for this study represented $\pm 10 \%$ of the new participant pool. 55 randomly selected participants attending the Tygerberg Oral Medicine clinic were included in this study. There were eight participants referred by specialists (ENT and Dermatologists) and for this study, these questionnaires were excluded. Three participants were below 18 years of age and the responses from their parents were not accepted as representing the participants' perception and were therefore excluded. Seven questionnaires were rejected due to participants having two choices marked in lieu of one choice. The questionnaires were handed out to all 55 participants who were waiting in the reception area prior to their appointment. A total of 37 correctly completed questionnaires were accepted after the aforementioned exclusions. Data management and statistical analysis were executed with the use of Microsoft Excel.

\section{RESULTS AND FINDINGS}

Participant choice of primary practitioner for orofacial symptoms.

Cross tabulations of the results were made. The responses to the questions posed in the questionnaire were evaluated in a $2 \times 3$ contingency table with the Pearson Chi-square test and two degrees of freedom in order to obtain the $p$-value. A $p<0.05$ was considered significant. The questions evaluated in the $2 \times 3$ were: "Who do you think to be the most able to treat problems of the mouth or jaws?" and "Who would you rather visit if you had a problem of the mouth/jaw? (excluding treatment to the teeth or gums)". For the question "Who do you think has had the most training in diseases of the mouth/face/ jaws? (excluding treatment to the teeth or gums)", a 3X3 contingency table was used (Table 1).

For the tabulation of results in Tables 1 and 2, the hypothesis was tested on the probabilities of choosing the GP rather than the dentist, in the three referring categories (referred by dentist, GP or own appointment made). The $p$-value yielded by the Chi-square test was greater than 0.05 (0.063).

Regarding the estimated probability of choosing the dentist as "the most able" practitioner, the participants referred by dentists and those who made their own appointments, are more likely to select the dentist. The probability of choosing the dentist was $12 / 13=0.92$ (Dentist referral); $7 / 13=0.54$ (GP referral) and $9 / 11=0.82$ (Own appointment made). Participants referred from their GP are less likely to choose the dentist as "the most able practitioner".

Table 1 outlines a cross tabulation of the participant's responses and their referring practitioner. $53.8 \%$ of patients indicated that they would rather visit a dentist if they had a mouth or jaw problem and $46.1 \%$ said they would rather visit a GP. The $p$-value of 0.258 indicated that there is no significant difference between choosing the medical practitioner over the dentist (for participants who were referred from the GP).

Table 1: Cross tabulation of participants' answers and referring practitioner

\begin{tabular}{|c|c|c|c|c|c|c|c|c|c|c|c|c|}
\hline & & \multicolumn{8}{|c|}{$\begin{array}{l}\text { Referred by Dentist / General medical practitioner } \\
\text { (GP)/ Made own Appointment }\end{array}$} & \multirow{3}{*}{$\begin{array}{l}\text { Chi } \\
\text { square }\end{array}$} & \multirow[b]{3}{*}{ df } & \multirow[b]{3}{*}{$\mathrm{p}$-value } \\
\hline & & \multicolumn{2}{|c|}{ Dentist } & \multicolumn{2}{|c|}{ GP } & \multicolumn{2}{|c|}{$\begin{array}{l}\text { Made own } \\
\text { Appointment }\end{array}$} & \multicolumn{2}{|c|}{ Total } & & & \\
\hline & & $n$ & (\%) & $\mathrm{n}$ & (\%) & $\mathrm{n}$ & (\%) & $\mathrm{n}^{*}$ & $(\%)^{\star *}$ & & & \\
\hline \multirow{2}{*}{$\begin{array}{l}\text { Who do you think to be the } \\
\text { most able to treat problems of } \\
\text { the mouth or jaws? (excluding } \\
\text { treatment to the teeth or gums) }\end{array}$} & GP & 1 & 7.6 & 6 & 46.1 & 2 & 18.1 & 9 & 24.3 & \multirow{2}{*}{5.5445} & \multirow{2}{*}{2} & \multirow{2}{*}{0.063} \\
\hline & Dentist & 12 & 92.3 & 7 & 53.8 & 9 & 81.8 & 28 & 75.6 & & & \\
\hline \multirow{2}{*}{$\begin{array}{l}\text { Who would you rather visit } \\
\text { if you had a problem of } \\
\text { the mouth/jaw? (excluding } \\
\text { treatment to the teeth or gums) }\end{array}$} & GP & 3 & 23 & 6 & 46.1 & 6 & 54.5 & 15 & 40.5 & \multirow{2}{*}{2.7097} & \multirow{2}{*}{2} & \multirow{2}{*}{0.258} \\
\hline & Dentist & 10 & 76.9 & 7 & 53.8 & 5 & 45.4 & 22 & 59.4 & & & \\
\hline \multirow{3}{*}{$\begin{array}{l}\text { Who do think has had the } \\
\text { most training in diseases of the } \\
\text { mouth/face/jaws? (excluding } \\
\text { treatment to the teeth or gums) }\end{array}$} & GP & 0 & 0 & 2 & 15.3 & 3 & 27.2 & 5 & 13.5 & \multirow{3}{*}{4.9073} & \multirow{3}{*}{4} & \multirow{3}{*}{0.297} \\
\hline & Dentist & 9 & 69.2 & 8 & 66.6 & 4 & 36.3 & 21 & 56.7 & & & \\
\hline & $\begin{array}{l}\text { Both GP } \\
\text { and Dentist }\end{array}$ & 4 & 30 & 3 & 23 & 4 & 36.3 & 11 & 29.7 & & & \\
\hline
\end{tabular}


Table 2: Cross Tabulation of Participants' Choice of Practitioner for Various Symptoms against Source of Referral

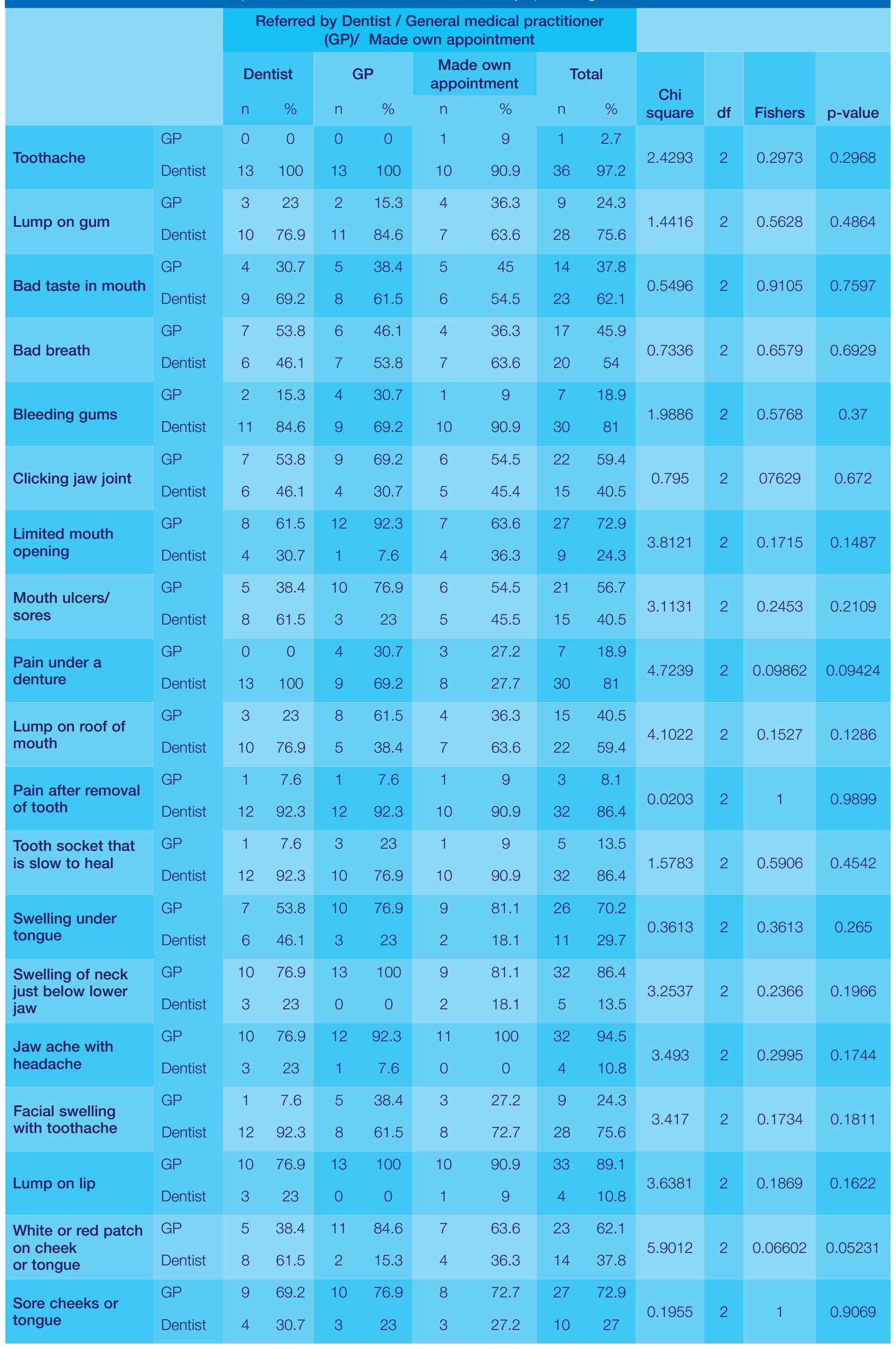


Participants were presented with a variety of orofacial symptoms and were asked who they would consult for these symptoms (Table 2). In most cases, for the obvious dental problems (such as toothache, lump on gum, bad taste in the mouth, bad breath, bleeding gums, pain under dentures, complications of tooth removal and toothache associated with facial swelling) participants chose to consult their dentist. For other orofacial symptoms, and symptoms that included extraoral involvement (such as clicking jaw joints, limited mouth opening, mouth ulcers, tongue swellings, neck swellings, jaw ache with headaches, lump on lip), participants chose to consult their GP. This can be linked to the likelihood that participants consider all these problems to fall out of the scope of dentistry.

However, Table 2 indicated a lack of consistency between the choice of primary care practitioner for the orofacial symptoms listed. The results for the observations as per Table 2 were done in $3 X 2$ contingency tables. The Pearson Chi-square was determined for every question asked (e.g. lump on gum, bad breath, etc.). These results were verified by the Fisher exact test as the frequencies were small and obtaining a $p$-value from Chi-square might have been inaccurate. The Fisher exact test resulted in the same conclusion as the Chi-square values.

Table 2 represented results that indicated a lack of significant difference between the choice of practitioner and referral source. The $\mathrm{p}$-value obtained from Chisquare above 0.05 confirmed the result. If a dentist referred a participant, the participant is more likely to select the dentist as the treating practitioner. The same trend exists for participants referred from GPs.

\section{Participant awareness of the proficiency of the dentist}

With regard to participants that chose their medical doctor as the primary practitioner it was important to note that $53.8 \%$ of participants thought that the dentist is most able to treat problems of the mouth or jaws (Table 1). $66.6 \%$ of participants regarded dentists as having the most training in diseases of the mouth, face or jaws and $23 \%$ of these participants agreed that both the doctor and dentist have training in diseases of the mouth, face or jaws (Table 1).

The participants' awareness of the proficiency of the dentist was determined by investigating their knowledge regarding the training dentists underwent to understand various diseases and procedures (Table 3 and 4). When referring to Table 3, participants had consensus that the dentist had education in diseases of the gums, jaw bones and joints; training in extracting teeth; training in anaesthetics; diseases of teeth, training in prevention of dental disease; training in dentures; training in filling teeth and training in gum treatment. The results were consistent for all the participants irrespective of whether they made their own appointments or referred from the dentist or medical practitioner. A large percentage (90.53\%) of participants referred from the medical practitioner confirmed that they thought the dentist had the most training in those conditions, yet from Table 1, 46.1\% of participants would still rather visit their medical practitioner if they had a problem related to the mouth/jaw/face.

Table 4 lists areas of training where the participants were uncertain of the expertise of the dentist. There was no consensus of the results indicating a misperception and/ or uncertainty of the proficiency of the dental practitioner. Notably, of the total participants, only $51.35 \%$ and $43.24 \%$ were aware of the training dentists have in HIV/AIDS and cancer, respectively. The percentage of participants indicating that they "do not know" and "false", indicates that the scope of practice of dental practitioners requires more attention regarding education and information provided to participants.

The referral pathway of participants attending the Tygerberg Oral Medicine Clinic

The results showed that $35.1 \%$ of participants attending the Tygerberg Oral Medicine Clinic were referred from their medical practitioner and that 35.1\% were referred from their dentist. $29.7 \%$ of participants had made their own appointment. From the initial study population of 55 participants, eight participants were referred by specialists (ENT and Dermatologists). Although these

Table 3: Areas that the Public is Aware of the Expertise of the Dentist

\begin{tabular}{|c|c|c|c|c|c|c|c|c|c|c|c|c|}
\hline \multirow{3}{*}{ Area/Aspect of training } & \multicolumn{9}{|c|}{$\begin{array}{l}\text { Referred by Dentist / General Medical practitioner (GP)/Own } \\
\text { Appointment }\end{array}$} & \multirow{2}{*}{\multicolumn{3}{|c|}{$\begin{array}{c}\text { Total } \\
\text { Percentage (\%) }\end{array}$}} \\
\hline & \multicolumn{3}{|c|}{ Referred by Dentist } & \multicolumn{3}{|c|}{ Referred by GP } & \multicolumn{3}{|c|}{$\begin{array}{l}\text { Made own } \\
\text { appointment }\end{array}$} & & & \\
\hline & True & False & $\begin{array}{l}\text { Don’t } \\
\text { Know }\end{array}$ & True & False & $\begin{array}{l}\text { Don't } \\
\text { know }\end{array}$ & True & False & $\begin{array}{l}\text { Don't } \\
\text { know }\end{array}$ & True & False & $\begin{array}{l}\text { Don’t } \\
\text { know }\end{array}$ \\
\hline Disease of gums & 13 & 0 & 0 & 12 & 0 & 1 & 11 & 0 & 0 & 97.30 & 0 & 2.70 \\
\hline $\begin{array}{l}\text { Disease of jaw bones and } \\
\text { joints }\end{array}$ & 11 & 0 & 2 & 11 & 1 & 1 & 8 & 1 & 2 & 81.08 & 5.40 & 13.51 \\
\hline Training in extracting teeth & 13 & 0 & 0 & 13 & 0 & 0 & 11 & 0 & 0 & 100 & 0 & 0 \\
\hline Training in anaesthetics & 10 & 2 & 1 & 8 & 3 & 2 & 9 & 1 & 1 & 72.90 & 16.22 & 10.81 \\
\hline Disease of teeth & 13 & 0 & 0 & 13 & 0 & 0 & 11 & 0 & 0 & 100 & 0 & 0 \\
\hline $\begin{array}{l}\text { Training in prevention of } \\
\text { dental disease }\end{array}$ & 12 & 0 & 1 & 12 & 0 & 1 & 10 & 0 & 1 & 91.89 & 0 & 8.12 \\
\hline Training in dentures & 13 & 0 & 0 & 12 & 0 & 1 & 11 & 0 & 0 & 97.30 & 0 & 2.70 \\
\hline Training in filling teeth & 13 & 0 & 0 & 13 & 0 & 0 & 11 & 0 & 0 & 100 & 0 & 0 \\
\hline Training in gum treatment & 13 & 0 & 0 & 12 & 1 & 0 & 11 & 0 & 0 & 97.30 & 2.7 & 0 \\
\hline Average Percentage (\%) & 94.6 & 1.69 & 3.38 & 90.53 & 4.23 & 5.07 & 93.90 & 2 & 4 & & & \\
\hline
\end{tabular}




\begin{tabular}{|c|c|c|c|c|c|c|c|c|c|c|c|c|}
\hline \multirow{3}{*}{$\begin{array}{l}\text { Area/Aspect of } \\
\text { training }\end{array}$} & \multicolumn{9}{|c|}{ Referred by Dentist / General Medical practitioner (GP)/Own Appointment } & \multirow{2}{*}{\multicolumn{3}{|c|}{$\begin{array}{c}\text { Total } \\
\text { Percentage (\%) }\end{array}$}} \\
\hline & \multicolumn{3}{|c|}{ Referred by Dentist } & \multicolumn{3}{|c|}{ Referred by GP } & \multicolumn{3}{|c|}{ Made own appointment } & & & \\
\hline & True & False & $\begin{array}{l}\text { Don't } \\
\text { Know }\end{array}$ & True & False & $\begin{array}{l}\text { Don't } \\
\text { know }\end{array}$ & True & False & $\begin{array}{l}\text { Don't } \\
\text { know }\end{array}$ & True & False & $\begin{array}{l}\text { Don't } \\
\text { know }\end{array}$ \\
\hline $\begin{array}{l}\text { Disease of salivary } \\
\text { glands }\end{array}$ & 10 & 3 & 2 & 6 & 4 & 3 & 7 & 2 & 2 & 62.16 & 24.32 & 18.92 \\
\hline Training in X-rays & 9 & 1 & 3 & 7 & 4 & 2 & 10 & 1 & 0 & 70.27 & 16.22 & 13.51 \\
\hline $\begin{array}{l}\text { Training in } \\
\text { antibiotics }\end{array}$ & 8 & 3 & 2 & 5 & 5 & 3 & 8 & 2 & 1 & 56.76 & 27.04 & 16.22 \\
\hline $\begin{array}{l}\text { Training in bacterial } \\
\text { disease }\end{array}$ & 8 & 2 & 3 & 8 & 4 & 1 & 7 & 2 & 2 & 62.16 & 21.62 & 16.21 \\
\hline Training in HIV/AIDS & 8 & 4 & 1 & 5 & 6 & 2 & 6 & 6 & 0 & 51.35 & 43.24 & 8.12 \\
\hline Disease of throat & 6 & 3 & 4 & 5 & 6 & 2 & 6 & 3 & 2 & 45.95 & 32.43 & 21.62 \\
\hline Disease of tonsils & 6 & 3 & 4 & 3 & 6 & 4 & 5 & 4 & 2 & 37.84 & 35.14 & 16.22 \\
\hline Training in cancer & 6 & 3 & 4 & 5 & 8 & 0 & 5 & 4 & 2 & 43.24 & 40.54 & 16.21 \\
\hline $\begin{array}{l}\text { Training in general } \\
\text { medicine }\end{array}$ & 5 & 7 & 1 & 5 & 3 & 5 & 6 & 5 & 0 & 43.24 & 40.54 & 16.21 \\
\hline Disease of sinuses & 4 & 3 & 6 & 1 & 8 & 4 & 5 & 3 & 3 & 27.03 & 37.84 & 35.14 \\
\hline $\begin{array}{l}\text { Average } \\
\text { Percentage (\%) }\end{array}$ & 53.84 & 24.61 & 23.07 & 38.46 & 41.53 & 20 & 59.09 & 29.09 & 12.72 & & & \\
\hline
\end{tabular}

questionnaires were excluded from the final sample size, the significance of the referral source remains. Clearly defined referral pathways for all health professionals have shown a reduction in delay of diagnosis and definitive treatment.

\section{DISCUSSION}

In this study, an equal percentage of participants were referred from their medical doctor (35.1\%) and their dentist (35.1\%) to the UWC Oral Medicine Clinic at Tygerberg. Irrespective of the referral source, the participants still thought the dentist was the most able to treat problems of the mouth and jaws (53.8\%). In terms of questions posed in Table 1, the trend was that participants referred by the dentist were more likely to choose the dentist as the preferred practitioner (92.3\%; 76.9\% and $69.2 \%)$. The same trend exists for those participants who were referred from their doctor and those that made their own appointment, but to a lesser degree than the dentist referrals. This can indicate a possible relationship between the referral source and accessibility, as participants referred from their GP may have found it easier to make an appointment with their doctor, as there may also be a doctor patient trust relationship already present. Nevertheless, patient preference of their primary pracitioner for orofacial symptoms and who they thought were most able to treat orofacial problems is largely dependent on their perception of the dentist. ${ }^{12,15}$ There is a perception that dentists only "perform routine extractions and fillings". Many people also avoid consulting their dentist because of their dental anxiety. ${ }^{15}$ Excessive dental anxiety can lead to avoidance strategies of patients to elude dental treatment, which can have dire consequences because of delayed diagnosis. ${ }^{16}$

Table 2 presented clinical scenarios and the participants' perception of which practitioner they would prefer to visit. The following scenarios and the participants' choice of GP or dentist being very similar is concerning (GP) Dentist: Bad breath 45.9/54; clicking of the jaw 59.4/40.5: mouth ulcers/sores $56.7 / 40.5$ and lump on the roof of the mouth 40.5/59.4). These data indicate that participants were aware of the capabilities of the dentist to treat problems related to the teeth and gums. However, their choice of primary practitioner for orofacial problems of non-dental origin is not clearly established as being either the GP or the dentist. These results obtained from the individual scenarios (Table 2) regarding the choices made is relevant considering that overall $75.6 \%$ of these participants indicated in that the dentist was most able to treat problems of the mouth and jaw (excluding the teeth and gums) versus the GP (Table 1). This could mean that the patient is not aware of the full scope of practice of a dental practitioner or that patients do have more faith in the ability of GPs over dental practitioners. ${ }^{12}$

The more obvious scenarios like toothache (2.7/97.2); bleeding gums (18.9/81); pain under a denture (18.9/81); pain after tooth removal (8.1/86.4); tooth socket not healing (13.5/86.4) and facial swelling with toothache (24.3/75.6) were predominantly chosen with the dentist as the treating practitioner. The possibility that the public still views dentists as only filling cavities and extracting teeth, ${ }^{7}$ instead of treating and managing orofacial diseases, should be considered.

When all the percentages of the various clinical scenarios from Table 2 are calculated, it becomes apparent that $47.3 \%$ chose the medical practitioner and $52.67 \%$ chose the dentist as the treating practitioner. This is concerning considering that the clinical scenarios depicted in Table 2 are all directly related to the scope of practice for the dental practitioner.

One of the most likely encounters with oral lesions is that of oral ulcers. A randomized study determined where members of the Israeli public may seek advice on mouth ulcers. ${ }^{4}$ The results indicated that the clear majority of the public (69\%) would first approach a general medical practitioner for advice where only $13-17 \%$ of the study participants would first approach a dentist. An even lesser number (4-10\%) would first go to a pharmacy for advice. Similarly, most of the participants in this current study $(56.7 \%)$ also chose to consult a medical practitioner for ulcers (Table 2). These results clearly indicate the lack of participant awareness regarding dentists having 
significantly more training and knowledge regarding the diagnosis and management of mouth ulcers than most medical or pharmaceutical practitioners. ${ }^{4}$

The participants' awareness of the proficiency of the dentist was determined by investigating their knowledge regarding the training dentists underwent to understand various diseases and procedures (Table 3 and 4).

Most participants were aware of the teaching offered in managing the common tasks of the dentist such as training in filling teeth (100\%), training in dentures (97.3\%), training in gum treatment (97.3\%) and training in extracting teeth (100\%). However, only a minor proportion of participants were aware of the training dentists have in HIV/AIDS (51.35\%) and cancer (43.24\%).

Participants were unaware of the extent of dental training. These extended areas included: diseases of the sinuses, salivary glands, throat, tonsils, antibiotics, cancer, x-rays, general medicine, HIV/AIDS and bacterial disease. Similarly, in a study carried out by Scully et al., patients failed to regard dentists as being trained in general medicine, cancer and HIV/AIDS. ${ }^{17}$ This is problematic as failure to consult the appropriate medical professional can result in delays in diagnosis and consequential delays in treatment. ${ }^{10}$

$59.4 \%$ of participants chose to consult a GP for a clicking jaw joint; however, $81.08 \%$ of participants agreed that dentists received adequate training in diseases of the jaw bones and joints. Participants lacked the ability to understand and associate some of the orofacial symptoms with their concepts of the training of the dentist. The possibility that the public still views dentists as only filling cavities and extracting teeth, ${ }^{7}$ instead of treating and managing orofacial diseases, should once again be considered. From this study, it can be deduced that there is a lack of understanding of the actual role and capabilities of the dentist to diagnose and treat orofacial disease.

Participant awareness and education regarding the capabilities of their dentist needs to be created to ensure better access to oral healthcare. Many participants were unaware of the proficiency in diagnosing and managing orofacial diseases of even a newly qualified dentist. ${ }^{9}$ To ensure efficient and timeous treatment a need for a referral pathway is required to assist GPs and dentists in making the best choice for their participants. ${ }^{10}$ This delay in treatment can lead to a delayed referral to the appropriate professional as well as a delay in the treatment. ${ }^{6,18}$ The delay to detect and definitively treat premalignant and cancer lesions can have a negative effect on the presenting symptoms of the oral condition. ${ }^{19}$

Emphasizing the impact of collaboration between the medical and dental professions will greatly improve both oral and systemic health. Participants with medical conditions such as HIV/AIDS, diabetes, rheumatoid arthritis and Sjogren's syndrome, to highlight a few, would benefit from such collaboration..$^{18} \mathrm{~A}$ more proactive approach from maxillofacial and oral surgeons and oral medicine specialists towards teaching medical undergraduate students should be undertaken. ${ }^{13}$

It is important to start at the fundamental level of university to allow for integration of modules and learning..$^{18}$ It has been shown that there is a lack of formal referral pathways and communication between general medical and dental practitioners. ${ }^{12}$ Improved communication between medical and dental professionals will allow delivery of effective care to participants. ${ }^{18}$

\section{CONCLUSION}

Participants at the Tygerberg Oral Medicine Clinic, who despite being referred from their GP, agreed that the dentist is more capable in treating orofacial symptoms. They perceived dentists to be well trained in obvious dental problems such as toothache, bleeding gums, extractions, and fillings. However, for non-dental problems or problems that manifested extra- and peri-orally such as jaw pain, neck swellings and lumps on the lips, participants indicated GPs to be better trained.

The participant choice of primary practitioner for orofacial symptoms is influenced by their awareness and perception of the proficiency of the dentist and in turn this affects their referral pathway.

It can be concluded that participants are unaware of the fact that the dentist is proficient in diagnosing and managing orofacial diseases as well as identifying oral manifestations of systemic disease. The idea that the expertise of the dentist is limited to extracting and filling teeth needs to be transformed to include diagnosing and treating orofacial disease.

\section{LIMITATIONS OF THE STUDY}

Limitations of the study included the fact that the specialist Oral Medicine clinic at Tygerberg $\mathrm{OHC}$ treats a relatively small number of new patients compared with the undiagnosed disease burden. Language barriers may have limited the study due to incorrect completed questionnaires in English only and some limited assistance in Afrikaans. The socio-economic status could limit the comprehension in understanding some terms, despite participants being English speaking and there was a possibility that the information was misinterpreted. The sample bias of patients also may have limited the study, as the patients were influenced by the fact that they had appointments at the Oral Medicine clinic. Age (>25 yrs vs < $25 \mathrm{yrs}$ ) and gender subgroups (Females vs Males) analyses were not recorded, since the sample size was too small to draw from the comparisons between referral sources.

\section{CONCLUDING REMARKS AND RECOMMENDATIONS}

The limitations do not diminish the rationale that public awareness about the scope, skills, training and therapies available from trained dentists should be promoted. Improved patient education regarding the proficiencies of the dentist is required. This should be cultivated and taught by dentists and other health care workers in practice. This research provides a pragmatic baseline for future research. This topic should be researched further with a larger sample size and in a more neutral setting.

\section{ETHICAL CONSIDERATIONS}

The study population included participants attending the Tygerberg Oral Medicine clinic at the UWC Dental Faculty. No incentives were offered for participation. Ethical consideration for the research study was obtained from the Dental Research Committee of the University of the Western Cape. 
The anonymity of all participants was ensured by allocated record numbers and written informed consent was obtained prior to their participation in the survey. An information sheet and consent form was distributed to the participants providing a brief background and reason for the study. The results obtained from the study will be used for educational and research purposes only.

\section{Conflict of Interest: None declared.}

\section{References}

1. Formicola AJ, Stavisky J, Lewy R. Cultural Competency: Dentistry and Medicine, Learning from one another. Journal of Dental Education 2003; 67(8): 869-75.

2. Adams T. Dentistry and Medical dominance. Social Science and Medicine 1999; 48(1): 407- 20.

3. Lavigne SE. Your mouth - portal to your body. Canadian Jounral of Dental Hygiene 2004; 38(3): 114-34.

4. Gill Y, Scully C. Mouth ulcers: a study of where members of the general publlic might seek advice. British Dental Journal 2007; 202(E16): 1-3.

5. Mansour MH, Cox SC. Participants presenting to the general practitioner with pain of dental origin. Medical Journal of Australia 2006; 185(2); 64-7.

6. Macpherson LM, McCann MF, Gibson J, Binnie VI, Stephen $\mathrm{KW}$. The role of primary healthcare professionals in oral cancer prevention and detection. British Dental Journal 2003; 195(5): 278-81.

7. McCann PJ, Sweeney MP, Gibbson J, Bagg J. Training in oral disease, diagnosis and treatment for medical students and doctors in the United Kingdom. British Journal of Oral and Maxillofacial Surgery 2005; 43(1): 61-4.

8. HPCSA [Internet]. Regulations defining the scope of the profession of dentistry - Government Gazette 31958; [updated 2009 Mar 6; accessed 2016 Nov 15]. Available from: http://www.hpcsa.co.za/uploads/editor/UserFiles/ REGULATIONS\%20DEFINING\%20THE\%20SCOPE\%20 OF\%20THE\%2OPROFESSION\%20OF\%20DENTISTRY.pdf

9. Plasschaert AJ, Holbrook WP, Delap E, Martinez C, Walmsley AD. Profile and competences for the European Dentist. European Journal of Dental Education 2005; 9(1): 98-107.

10. McLeod NM, Saeed NR, Ali EA. Oral Cancer: Delays in referral and diagnosis persist. British Dental Journal 2005; 198(11): 681-4

11. Angela C, Neville BW, Krayer JW, Gonsalves WC. Oral manifestations of systemic disease. American Family Physician 2010; 82(11); 1381-8.

12. Bell GW, Smith GL, Rodgers JM, Flynn RW, Malone $\mathrm{CH}$. Participant choice of primary care practitioner for orofacial symptoms. British Dental Journal 2008; 204(12): 669-73.

13. Carter LM, Ogden GR. Oral cancer awareness of general medical and general dental practitioners. British Dental Journal 2007; 203(10); 1-5.

14. Schmidt-Westhausen AM, Bornstein MM. Oral Medicine: Interdisciplinary collaboration between medicine and dentistry. Springer Medizin Verlag 2011; 1-9.

15. Liu M. The Dentist / Participant Relationship: The Role of Dental Anxiety. [Thesis] Claremont McKenna College; 2011.

16. Eitner S, Wichmann M, Paulsen A, Holst S. Dental anxiety - an epidemiological study on its clinical correlation and effects on oral health. Journal of Oral Rehabilitation 2006; 33(1); 588-93.

17. Scully C, Bell C, Porter K, Porter S. Views of dental participants about the education and practice of dentists. Community Dentistry and Oral Epidemiology 1994; 22(1): 112-3.

18. Migliorati CA, Madrid C. The interface between oral and systemic health: the need for more collaboration. Clinical Microbiology and Infection 2007; 13(4): 11-6.

19. Van Heerden WFP, van Zyl AW. The role of the dentist in the early detection of oral cancer.South African Dental Journal 2011, 66(8): S1- S4.

\section{6) 6) (6) JONUSINNEW ZEALANDANDHAVEA LFESTML ETO ENM The Dentists love your smile}

\section{NEW ZEALAND PASSENGER ARRIVAL CARD}

Rated in the top ten safest countries in the world - New Zealand is the place where you can enjoy beaches, parks, award-winning wine, world-class restaurants and a range of cultures right on your doorstep - literally.

New Zealand has that perfect combination of big city and country town all rolled into one. With a great community feel, excellent schooling and a thriving economy - New Zealand really is a place that you can call home.

With 91 practices nationwide there are opportunities everywhere to enjoy the lifestyle you want, plus enjoy:

(d) Excellent salary, standard of living and work/life balance

(d) Lucrative earning potential in smaller towns

() Career advancement and development within the Lumino Group

1 We need talented

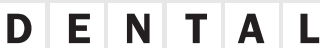
C L I $\mathbf{N}$
C I

A $\mathbf{N}$ to start

A S A P

2 For further information:

$\begin{array}{llllllllllllllllllllllllll}\text { C } & \text { A } & \mathbf{R} & \mathrm{E} & \mathrm{E} & \mathbf{R} & \mathbf{S} & . & \mathbf{L} & \mathbf{U} & \mathbf{M} & \mathbf{I} & \mathbf{N} & \mathbf{0} & . & \mathbf{C} & \mathbf{0} & . & \mathbf{N} & \mathbf{Z}\end{array}$ 